Vidya Wertta Volume 2 Nomor 2 Tahun 2019

https://ejournal.unhi.ac.id/index.php/vidyawertta

\title{
INTERPRETASI NILAI FILOSOFIS TEKS SRI JAYAKASUNU
}

\author{
ANAK AGUNG GEDE DIRA \\ I WAYAN WAHYU JULIANTARA \\ Fakultas Ilmu Agama, Seni dan Budaya \\ Universitas Hindu Indonesia \\ agungdira@unhi.ac.id
}

\begin{abstract}
ABSTRAK
Ajaran agama Hindu di Bali bersumber dari karya sastra tradisional. Karya sastra merupakan sumber yang tertulis dalam mengetahui ajaran keagamaan. Dalam penelitian ini karya sastra Sri Jayakasunu digunakan sebagai objek penelitian. Penelitian ini menggunakan rancangan penelitian kualitatif dengan metode pengumpulan data berupa studi kepustakaan dan metode wawancara. Dalam teknik analisis data menggunakan teknik analisis deskritif, yaitu mendeskripsikan secara sistematis dalam menyusun dengan aturan-aturan tertentu. Hasil penyajian analisis penelitian ini membahas tentang beberapa hal, yaitu interpretasi nilai filosofis dari teks Sri Jayakasunu dan relevasnsinya terhadap hari raya Galungan adalah a) nilai kebenaran (tatwa) yang mana menunjukan bahwa konsep dari Panca Sradha harus selalu digunakan sebagai landasan kehidupan didunia. b) nilai kesusilaan yang selalu melaksanakan konsep Tri Kaya Parisudha, dan dalam implementasinya kepada Tri Hita Karana; dan c) nilai acara (upacara) sebagai sarana mewujudkan syukur dan bakti kepada Tuhan dengan jalan melaksanakan kegiatan Yadnya.
\end{abstract}

Kata Kunci: interpretasi, nilai filosofi, jayakesunu

\section{PENDAHULUAN}

Bali memiliki berbagai jenis naskah kuno yang disimpan baik di lembagalembaga formal maupun perorangan. Naskah lontar ini umumnya berbagai jenis seperti : tutur (tatwa), Kanda, Usada, Wariga, Babad, dan lain-lain. Yang menarik di sini untuk dijadikan objek penelitian adalah tentang jenis tutur (tatwa) yang merupakan bagian dari naskah-naskah keagamaan, ritual, dan etika. Berbagai jenis lontar tutur memunculkan ajaran-ajaran filsafat dan agama serta susila yang pada umumnya menguraikan tentang ajaran ke-Tuhanan atau Widhi Tatwa pengaturan upacara, ilmu pengetahuan umum maupun kesenian atau ajaran tentang penciptaan alam semesta. Dari sekian banyak naskah-naskah lontar yang berbicara 
masalah tutur, dalam penelitian ini, ada ketertarikan peneliti untuk mengkaji naskah yaitu Sri Jayakasunu, yang tersimpan dan terdapat di Pusat Dokumentasi Dinas Kebudayaan Provinsi Bali, yang menarik untuk diteliti dari segi teks tersebut menceritakan tentang bagaimana Sri Jayakasunu ingin mengetahui penyebab dari bencana dan penyakit yang menimpa rakyat Bali, dengan melaksanakan ritual Dewaseraya dan hingga akhirnya mendapatkan pawisik dari Bhatari Durga, tentang perihal penyebab terjadinya bencana yang menimpa rakyat Bali, yaitu ketidak ingatan mereka untuk melaksanakan yadnya saat perayaan hari raya suci Galungan. Dalam teks Sri Jayakasunu menjelaskan bahwa tradisi agama di Bali Galungan tersebut tidak dilaksanakan seperti sedia kala. Hal itu yang menjadi pemicu kerancuan serta ke tidak teraturan dalam tatanan kehidupan masyarakat di Bali.

Penelitian ini memiliki keunikan tersendiri yaitu memberikan suatu pandangan yang bersifat kontruktif bagi pemahaman bersama sebagai umat Hindu yaitu Makrokosmos (alam besar) yang sangat terikat dengan Mikrokosmos (alam kecil). Untuk menjaga alam makro tentunya diawali dengan menjaga keharmonisan alam mikro. Keharmonisan itu dapat di lestarikan dengan mengaplikasikan ajaranajaran tradisi di Bali. Tradisi di Bali menjadi kekuatan terhadap keharmonisan alam semesta dengan pelaksanaan ritual-ritual yadnya.

Dari uraian di atas muncul suatu keingian untuk melakukan penelitian lebih dalam tentang teks Sri Jayakasunu dengan harapan dapat menginterpretasi dan mendapatkan nilai Filosofisnya, dengan harapan mengetahui secara jelas bagaimana perayaan Hari Raya Suci Galungan tersebut yang dinyatakan atau disebutkan dalam teks Sri Jayakasunu. Agar menjadikan pemahaman tentang hal tersebut jelas untuk diungkap melalui karya sastra.

Harapan peneliti dengan penelitian ini, agar dapat menjadi suatu penelitian yang berguna untuk kalangan masyarakat umum, sebagai suatu pemahaman awal dalam menyikapi pelaksanaan dari Agama Hindu, seperti mengetahui, mengapa umat Hindu melaksanakan Hari Raya Suci Galungan, pertanyaan seperti itu banyak muncul di kalangan masyarakat yang masih awam, karena ketidaktahuannya tentang tatwa-tatwa dari pelaksanaan-pelaksanaan ritual keagamaan itu sendiri khususnya agama Hindu.

\section{PEMBAHASAN}

\subsection{Interpretasi Nilai Filosofis dalam Teks Sri Jayakasunu}

Sebuah teks sastra kuno yang membicarakan tentang kehidupan atau yang mempunyai peranan bagi kehidupan di Dunia ini. Pentingnya sebuah interpretasi (tafsir) teks itu sendiri merupakan suatu langkah awal untuk mengetahui apa yang dimaksud oleh teks sastra itu sendiri. Teks Sri Jayakasunu merupakan salah satu teks yang mengupas mengapa masyarakat di Bali khususnya melaksanakan perayaan hari raya Galungan. Dalam teks ini menceritakan tentang bagaimana Sri Jayakasunu mendapat pawisik dari Bhatari Durga tentang mengenai bencana yang menimpa masyarakat Bali, akibat lupa akan kewajiban kepada Ida Sang Hyang Widhi Wasa tidak melaksanakan hari raya Galungan. Dalam teks ini terdapat nilai-nilai filosofis yang dapat di interpretasikan sebagai berikut: 


\section{Nilai Kebenaran (Tatwa)}

Wojowasito dalam Ariwidayani (2013: 19) pada kamus kawi Jawa KunoIndonesia bahwa tatwa diartikan sebagai kebenaran, hakekat, riwayat dan cerita. Menurut Rudia dalam Dwipayanti (2012: 78) menyatakan bahwa tatwa adalah inti atau kebenaran dasar ajaran agama.Tatwa merupakan kebenaran dalam agama Hindu yang penting untuk diketahui.

Sumber-sumber ajaran tatwa adalah pustaka-pustaka Hindu yang merupakan sumber atau asal ajaran kebenaran atau kenyataan. Tatwa adalah ilmu filsafat. Yang menjadi bagian terpenting dalam tatwa adalah ajaran Panca Sradha yaitu lima dasar kepercayaan dan keyakinan umat Hindu. Tanpa menghayati dan memahami Panca Sradha maka umat Hindu tidak memiliki keyakinan yang kuat. Lima dasar keyakinan agama Hindu yang disebut Panca Sradha yaitu (1) percaya dengan adanya Brahman (Tuhan), (2) percaya dengan adanya atman yang memberi kehidupan bagi semua mahluk, (3) percaya dengan adanya Karma Phala yaitu baik buruk suatu perbuatan yang akan menentukan kehidupan selanjutnya, (4) percaya dengan adanya punarbawa atau kelahiran berulang, yang dipengaruhi oleh karma phala, (5) percaya dengan adanya moksa yaitu tujuan akhir dari agama Hindu menyatunya atman dengan Brahman suatu kedamaian abadi.

Tatwa secara etimologi berasal dari bahasa Sanskerta yang berarti kebenaran, kenyataan sebenarnya, sesungguhnya, sungguh-sungguh, hakekat hidup. Menurut Watra dalam Poniman (2012: 67) menyatakan tatwa merupakan suatu kebenaran, perlu diketahui bahwa antara tatwa agama dengan kebenaran ilmiah berbeda, karena kebenaran agama terkait religiusitas. Ia menyimpulkan pengertian tatwa yaitu merupakan kebenaran yang bersifat abstrak (niskala) dan kongkret (skala) yang dapat dibuktikan secara rasional dan nyata. Selanjutnya Pudja dkk, dalam Ariwidayani (2013: 19) menyatakan bahwa istilah tatwa berasal dari bahasa Sanskerta yang dalam statusnya sebagai noun-masculine mengandung maksud "azas-azas atau intisari kebenaran sejati.

Berdasarkan konsep tatwa diatas bahwa tatwa merupakan intisari kebenaran sejati, dan hubungannya dengan penelitian ini adalah bagaimana manusia untuk menemukan kebenaran sejati sehingga memperoleh suatu kesempurnaan hidup dan memperoleh suatu kesadaran tentang jati diri dan tujuan hidup sebagai manusia, tatwa merupakan uraian filosofis tentang ajaran-ajaran yang tersimpul dalam Panca Sradha. Ajaran tersebut dapat diperhatikan dalam kutipan berikut ini:

"Singgih palulun, pasang tabe patik Bhatari umatur, marmane patik Bhatari, neda nugraha Bhatari tumiba maring pun Sri Jayakasunu, ring kadirga yusaning anyeneng Ratu. Mwah kaluarining jaramarana, nging paduka Bhatari juga anulakaken jaramarana" (Sri Jayakasunu, 2a).

Terjemahan:

Ya Hyang Bhatari, mohon maaf hamba berkata, apa yang menyebabkan hamba memohon kehadiran Hyang Bhatari di hadapan hamba, untuk memohon kedirgayusan dalam memerintah kerajaan, dan agar segala bencana menjauh dari hamba dan juga hamba memohon agar hyang Bhatari menghadang bencana yang terjadi. 
Berdasarkan kutipan di atas Sang Sri Jayakasunu memohon kedirgayusan kepada Bhatari Durga agar terhindar dari segala bencana dan wabah penyakit. Menunjukan sifat Tuhan Yang Maha Esa, Maha Kuasa, dan Maha Segalanya. Sri Jayakasunu sangat percaya akan kebenaran dari eksistensi Tuhan. Berdasarkan uraian di atas dapat di ungkapkan bahwa unsur nilai Tatwa dalam teks Sri Jayakasunu menyampaikan tentang ajaran Panca Sradha yakni lima unsur keyakinan yang merupakan inti ajaran agama Hindu yang terdiri dari:

1. Brahman yakni percaya dengan eksistensi Tuhan (Ida Sang Hyang Widhi Wasa), yang kuasa atas segala yang ada di dalam kehidupan ini, tidak ada yang luput dari kuasanya. Berdasarkan isi teks Sri Jayakasunu, kepercayaan terhadap kuasa Bhatari Durga merupakan wujud implementasi keyakinan terhadap Brahman

(Tuhan). Sebab Dewata merupakan "div" atau yang berarti sinar suci dari Brahman dalam peranannya sebagai hukum alam semesta, sehingga semua umat di Bali khususnya yang beragama Hindu menyebah dan berbakti dengan berbagai cara pada tempat yang berbedabeda atas ke-Maha Kuasaan beliau yang disebut dengan Cadhu Sakti. Cadhu Sakti adalah empat ke-Maha Kuasaan Tuhan yang

terdiri dari:

a) Wibhu Sakti adalah sifat Tuhan atau Ida Sang Hyang Widhi Wasa Maha Ada, meresap memenuhi Bhuwana atau Wyapi Wyapaka/berada di manamana, tiada tempat yang tidak dipenuhi oleh wujud-Nya. Wyapi Wyapaka Nirwikara artinya selalu ada di mana-mana tidak terpengaruh dan tidak berubah.

b) Prabhu Sakti adalah Ida Sang Hyang Widhi bersifat Maha Menguasai alam semesta sebagai pencipta (Utpeti), pemeliharaan (Shtiti), dan pelebur (Pralina) atas ciptaan-Nya. Begitupun pada teks Sri Jayakasunu, Tuhan yang memberikan penyakit, Tuhan pula yang memberikan anugrah.

c) Jnana Sakti adalah sifat Ida Sang Hyang Widhi Wasa yang Maha Tahu. Ida Sang Hyang Widhi Wasa mengetahui segala kejadian dan segala yang ada di alam baik yang nyata (realitas) maupun yang tidak nyata. Tuhan mampu mengetahui kejadian masa lampau, kejadian sekarang dan mampu mengetahui kejadian yang akan datang.

d) Kriya Sakti adalahsifat Ida Sang Hyang Widhi Wasa yang Maha Karya. Ida Sang Hyang Widhi Wasa dapat berbuat apa saja yang dikehendakiNya. Ida Sang Hyang Widhi Wasa menciptakan alam semesta ini dengan Kemahakuasaan-Nya dan akan kembali kepada-Nya. Sebelum Dunia ini diciptakan pada mulanya adalah kosong tidak ada apa-apa (Duk Tan Hana Paran-Paran) yang ada hanya Ida Sang Hyang Widhi Wasa beliau tidak pernah berhenti bekerja. Seperti yang diceritakan dalam teks Sri

Jayakasunu, Ida Sang Hyang Widhi pula yang memberikan bencana, dan Tuhan pula yang menciptakan berbagai keindahan pada alam semesta ini. 
2. Atman yakni percaya akan keberadaan Jiwatman (Atman). Atman adalah percikan kecil Brahman. Bila Atman meninggalkan badan kasar (Stula Sarira) mahluk hidup pasti akan meninggal/mati. Atman yang menghidupkan badan disebut Jiwatman. Jiwatman dapat dipengaruhi oleh karma hasil perbuatan di Dunia (Ngurah, dkk, 1993: 60). Seperti pada kutipan teks Sri Jayakasunu sebagai berikut:

"Ling Bhatari: uduh sira Sri Jayakasunu, ulun awarah-warah mareng kita. Marmane asiong anyeneng ratu ring Bali agelis pejah, apanira ri kala teluning dunggulan tan ana abaya kala, nora anut kramane nguni. Ya ika ta asing anyeneng ratu, during rong taun mawetu pejah tekaning wadwania kabeh, pada telas pejah ya tiba jaramarana dening pada Batara, apan paranoia kayangan pada Batara. Mwah kabyutan tekaning pangastanan telas pada rusak tan ana kadi ring kuna-kuna. (Sri Jayakasunu, 2a).

Terjemahan:

Bersabda Bhatari Durga: "wahai anakku Sri Jayakasunu sekarang aku memberikan wejangan kepadamu, apa sebab setiap yang menjadi raja di Bali cepat meninggal, sebab pada waktu wuku Dunggulan tidak ada seorangpun yang melaksanakan upacara byakala, tidak seperti waktu dulu. Setiap yang menjadi raja di Bali belum dua tahun sudah meninggal serta pengikutnya semua, semua terkena wabah penyakit oleh Tuhan sebab kotornya kayangan dan juga pelinggih-pelinggih semua rusak tidak seperti dahulu.

Berdasarkan kutipan teks di atas Ida Sang Hyang Widhi Wasa yang memberikan kehidupan dan Beliau juga yang mengambil karena semuanya berasal dari Beliau dan kembali pula pada Beliau karena semuanya merupakan ciptaan-Nya.

3. Karmaphala adalah keyakinan untuk mempercayai adanya hukum sebab akibat, Karmaphala berarti hasil yang di dapat dari perbuatannya. Akibat yang baik akan membawa kesenangan dan akibat buruk akan berdampak kesusahan atau penderitaan, karena setiap perbuatan yang kita lakukan pasti akan mendapatkan hasilnya. Hasil perbuatan pun di bedakan menjadi yang dinikmati pada waktu yang berbeda: perbuatan di masa lampau/kehidupan lalu pada kehidupan sekarang kita terima hasilnya (Sancita Karmaphala), perbuatan yang dilakukan sekarang, sekarang juga kita terima hasilnya (Prarabda Karmaphala), dan perbuatan pada kehidupan sekarang belum habis diterima hasilnya maka akan kita terima pada kehidupan yang akan datang (Kriyamana Karmaphala), seperti pada kutipan teks Sri Jayakasunu berikut ini:

"Ling Bhatari: uduh sira Sri Jayakasunu, ulun awarah-warah mareng kita. Marmane asiong anyeneng ratu ring Bali agelis pejah, apanira ri kala teluning dunggulan tan ana abaya kala, nora anut kramane nguni. Ya ika ta asing anyeneng ratu, during rong taun mawetu pejah tekaning wadwania kabeh, pada telas pejah ya tiba jaramarana dening pada Batara, apan paranoia kayangan 
pada Batara. Mwah kabyutan tekaning pangastanan telas pada rusak tan ana kadi ring kuna-kuna. (Sri Jayakasunu, 2a).

Terjemahan:

Bersabda Bhatari Durga: "wahai anakku Sri Jayakasunu sekarang aku memberikan wejangan kepadamu, apa sebab setiap yang menjadi raja di Bali cepat meninggal, sebab pada waktu wuku Dunggulan tidak ada seorangpun yang melaksanakan upacara byakala, tidak seperti waktu dulu. Setiap yang menjadi raja di Bali belum dua tahun sudah meninggal serta pengikutnya semua, semua terkena wabah penyakit oleh Tuhan sebab kotornya kayangan dan juga pelinggihpelinggih semua rusak tidak seperti dahulu.

Seperti kutipan di atas bagaimana rakyat Bali pada waktu itu tidak menjalankan kembali perayaan Galungan. Tuhan menciptakan serta memberikan alam semesta beserta seluruh isinya berlandaskan dengan pelaksanaan Yadnya atau persembahan yang suci dengan penuh cinta kasih. Jika Tuhan menegakka Dharma-Nya dalam mengatur keharmonisan alam semesta, maka manusia pun hendaknya menjalankan swadharmanya sebagai umat Hindu yang telah memiliki tradisi sejak awal, guna menjaga keharmonisan tatanan alam semesta dengan perilaku yang positif. Hal ini tertuang dalah kitab Bhagavad Gita yang dapat diperhatikan sebagai berikut:

Sreyan sva dharmo vigunah

Para dharmat svanusthitat

Sva dharmo nidhanam sreyah

Para dharmo bhayavahah

(Bhagavad Gita, 3.35)

Terjemahan:

Jauh lebih baik melaksankan tugas-tugas kewajiban yang sudah ditetapkan untuk kita, walaupun kita berbuat kesalahan dalam tugas-tuga itu, dari pada melakukan tugas kewajiban orang lain secara sempurna. Kemusnahan sambil melakukan tugas kewajiban sendiri sendiri lebih baik dari pada menekuni tugas kewajiban orang lain, sebab mengikuti jalan orang lain berbahaya (Prabhupada, 1971: 199)

Merayakan hari raya Galungan merupakan wujud rasa syukur kita terhadap segala kehidupan yang diberikan leluhur kita sendiri, wujud melaksanakan konsep Tri Hita Karana, yaitu membinta hubungan yang baik kepada Ida Sang Hyang

Widhi Wasa dalam wujud bhakti mempersembahkan Upakara atau Banten. Kedua adalah membina hubungan yang baik terhadap sesama manusia, dilihat dari pelaksanaan persembahyangan bersama sanak saudara ketika Galungan. Ketiga adalah membina hubungan yang baik dengan alam semesta/lingkungan atau Bhuta Kala, yang dapat di 
visualisasikan dengan pelaksanaan pemberian sesajen untuk para Bhuta Kala pada saat Anggara (selasa) Wage wuku Dunggulan.

4. Punarbhawa, yakni percaya akan kelahiran kembali, Punarbhawa berasal dari kata Punar yang berarti kembali dan Bhawa yang berarti menjelma/lahir.

Punarbhawa juga sering disebut dengan Reinkarnasi. Seperti kutipan kitab

Sarasamuscaya berikut ini:

Iyam hi yonih prathama yonih praoya jagatipate

Atmanam sakyate tratum karmabhih subha laksanaih

Apan ikang dadi wwang, uttama juga ya, nimittning mangkana

Wnan ya tumulun awaknya sanken sansara, maka sadhanan subhakarma, hinan in kottamanin dadi wwang ika

(Sarassamuscaya,

Terjemahan:

Menjelma sebagai manusia itu adalah sungguh-sungguh utama. Sebab demikian, karena ia dapat menolong dirinya dari samsara dengan jalan berbuat baik. Demikian keuntungan menjelma menjadi manusia.

Setiap roh yang ada dalam diri mahkluk hidup selalu mengalami perpindahan dari badan yang satu ke badan yang lainnya. Seperti halnya yang terdapat dalam kitab Bhagavad Gita sebagai berikut:

Dehino smin yatha de he

Kaumaram yauvanam jara

Tatha dehantara praptir

Dhiras tatra na muhati

Terjemahan:

(Bhagavad Gita, 2. 13)

Seperti halnya sang roh terkurung di dalam badan, terus menerus mengalami perpindahan, di dalam badan ini dari masa kanak-kanak, sampai masa remaja sampai usia tua, begitu juga sang roh masuk ke dalam badan lain pada waktu meninggal. Orang yang tenang tidak bingung karena penggantian itu (Prabhupada, 1971: 89).

Berdasarkan sloka tersebut dapat dipetik nilai tatwa bahwa perpindahan roh ke tubuh yang baru sesuai dengan karmanya terdahulu, guna mencapai peningkatan kualitas diri, 
sehingga semua karma terbayar dalam kelahiran demi kelahiran, sehingga mencapai tujuan sejati kehidupan yaitu Jiwanmukti.

5. Moksa, yang berarti kelepasan untuk mencapai kebahagiaan yang abadi. Konsep kepercayaan terhadap adanya Moksa merupakan tujuan akhir yang ingin dicapai para pemeluk agama Hindu. Orang yang telah mencapai Moksa tidak akan terlahir lagi ke dunia. Karena ia telah menyatu dengan Brahman (Ngurah, dkk, 1993: 62). Dalam pelaksanaan hari raya Galungan khususnya di Bali sesungguhnya mempunyai kaitan yang menjadi atau sebagai jembatan bagi umat Hindu untuk melaksanakan Sradha dan Bhakti dalam upaya mencapai kebahagiaan abadi baik di dunia maupun di akhirat. Kebahagiaan abadi yang dicapai seseorang selama hidup di dunia atau disebut dengan Jiwamukti ditandai dengan kondisi pikiran dan perasaan yang selaras dan juga seimbang dengan frekuensi hukum alam yaitu bahagia (ananda). Dengan demikian, karma untuk terlahir kembali telah terbayar. Dalam hal ini terjadi penunggalan antara Atman dengan Brahman yang disebut dengan Brahman Atman Aikhyam.

Nilai kebenaran (tatwa) yang disampaikan dalam teks Sri Jayakasunu, mengajarkan bahwa sebagai umat Hindu mempunyai keyakinan yang berpedoman kepada nilai Panca Sradha, yaitu percaya terhadap Tuhan, Atman, Karmaphala, Punarbhawa, dan Moksa. Karena kelima komponen tersebut di atas merupakan landasan bagi umat Hindu untuk mencapai tujuan kehidupan yang lebih tinggi.

\section{Nilai Kesusilaan}

Secara etimologi kata Susila berasal dari kata "Su" dan "Sila", Su yang berarti baik, dan Sila yang berarti tingkah laku. Sehingga Susila berarti aturan-aturan atau tingkah laku yang baik mengenai perilaku yang baik, pikiran yang baik, dan juga perkataan yang baik. Segala perkataan dan juga perlaku bersumber dari bagaimana kondisi dari pikiran setiap individu. Kebiasaan seseorang atau individu untuk selalu mengkondisikan pikirannya untuk selalu positif, maka dengan senantiasa perkataan dan perilakunya akan selalu positif dan begitu juga sebaliknya, yang dapat dicermati dalam kutipan Sarasamuscaya di bawah ini:

\section{Mano hi mulam sarvesam indriyanam prawartate \\ Subhasubhasvavasthasu karyam tat survyavasthitam}

(Sarasamuscaya, 80)

Terjemahan:

Pikiran itu adalah sumber indriyanya, yang menggerakkan perbuatan baik dan buruk. Karena pikiran itu patut untuk dikendalikan secepatnya. 
Dalam pernyataan kutipan teks Sarasamuscaya di atas, memang sejatinya bahwa apapun yang terlaksana dalam kehidupan ini merupakan bersumber dari pikiran, bagaimana pikiran yang mengendalikan atau bagaimana pikiran mengkondisikan apa yang akan terjadi. Dalam kitab Manawa Dharmasastra menyatakan bahwa:

\section{Tri dandam metan niksipya \\ Sarwabhutesu manawah \\ Kamakrodhau tu samyamya \\ Tatah siddhimniyacchati}

Terjemahan:

$$
\text { (Manawa Dharmasastra, XII-11) }
$$

Orang yang dapat mengendalikan ketiganya yaitu, pikiran, perkataan, perbuataannya dan sepenuhnya telah menundukkan keinginan dan kemarahannya, maka ia akan mencapai keberhasilan yang sempurna.

Susila sebagai pedoman hidup di dunia ini agar manusia dapat melaksanakan sesuatu sesuai dengan aturan-aturan yang menjadi dasar manusia itu bertindak, yang perlu diperhatikan dan dilaksanakan karena sangat penting untuk mewujudkan suatu karma (perbuatan) yang sesuai dengan kaidah-kaidah ajaran kesusilaan. Seperti kutipan teks Sri Jayakasunu berikut ini:

Marmane asiong anyeneng ratu ring Bali agelis pejah, apanira ri kala teluning dunggulan tan ana abaya kala, nora anut kramane nguni. Ya ika ta asing anyeneng ratu, during rong taun mawetu pejah tekaning wadwania kabeh, pada telas pejah ya tiba jaramarana dening pada Batara, apan paranoia kayangan pada Batara. Mwah kabyutan tekaning pangastanan telas pada rusak tan ana kadi ring kuna-kuna. (Sri Jayakasunu, 2a).

Terjemahan:

Apa sebab setiap yang menjadi raja di Bali cepat meninggal, sebab pada waktu wuku Dunggulan tidak ada seorangpun yang melaksanakan upacara byakala, tidak seperti waktu dulu. Setiap yang menjadi raja di Bali belum dua tahun sudah meninggal serta pengikutnya semua, semua terkena wabah penyakit oleh Tuhan sebab kotornya kayangan dan juga pelinggih-pelinggih semua rusak tidak seperti dahulu.

Pada kutipan teks di atas dapat dilihat bagaimana rakyat Bali pada waktu itu tidak menjaga kesucian Kahyangan dan juga pelinggih-pelinggih semua rusak padahal Pura atau pelinggih merupakan tempat berstananya Ida Sang Hyang Widhi Wasa. Berdasarkan analisa penelitian, pelinggih-pelinggih yang ada di Bali tidak terjaga kesuciannya diakibatkan oleh masyarakat pada saat itu terkena pengaruh konsep-konsep Raja yang tidak memperhatikan nilai-nilai kesusilaan yang telah tertanam sejak awal. Perliku Raja yang tidak berkesesuaian dengan 
Dharma itu sebabnya yang harus diperbaiki sehingga konsep dari pelaksanaan Yadnya di Bali tetap terlaksana seperti pelaksanaan upacara Galungan, peduli terhadap kondisi tempat suci. Sebab tempat suci atau Pura di Bali seharusnya menjadi pusat kegiatan kerohanian yang nantinya berpengaruh kepada lingkungan.

Konsep dasar yang menjadi landasan kesusilaan bagi umat Hindu adalah ajaran Tri Kaya Parisudha. Jika ajaran ini diimplentasikan akan menuntun manusia dalam setiap langkahnya, mulai dari berfikir yang baik, berbicara yang baik, dan berbuat atau berprilaku yang baik. Tri Kaya Parisudha yang berasal dari kata "Tri" yang berarti tiga, "Kaya" berarti perilaku atau perbuatan, dan "Parisudha" berarti bersih, baik, suci, jadi Tri Kaya Pasrisudha berarti tiga perilaku manusia yang harus disucikan. Yang terdiri dari Manacika yang berarti berfikir yang baik, Wacika berarti berbicara yang baik, dan Kayika berarti berbuat yang baik.

a. Manacika berfikir yang baik, pikiran adalah sesuatu hal yang paling pokok yang menimbulkan adanya perkataan dan perbuatan. Selalu berfikir yang baik sehingga nafsu atau keinginan buruk yang timbul karena pengaruh lingkungan dan Panca Indrya dapat ditiadakan.

b. Wacika, berkata atau berbicara yang baik, karena setiap kata-kata dapat menyebabkan yang baik dan yang buruk. Kata-kata yang baik akan menyenangkan banyak orang, dan begitu juga sebaliknya, maka dari itu setiap orang wajib untuk selalu berkata ataupun berbicara yang baik, yang dapat menyebabkan kebahagian.

c. Kayika, berbuat yang baik, setiap perbuatan baik ataupun buruk akan menimbulkan karma, perbuatan yang baik akan mendapatkan hasil yang baik, dan begitu juga sebaliknya, perbuatan yang buruk akan mendapatkan hasil yang sama dengan perbuatannya.

Realisasi dari ajaran Susila harus menjadi pedoman dalam kehidupan seharihari, karena susila yang berkembang di masyarakat berisi aturan atau norma-norma tentang bagaimana bertingkah laku dalam kehidupan seperti selalu bertindak atau bertingkah laku, sehingga kerukunan, ketentraman dan kedamaian dalam kehidupan masyarakat dapat tercipta sesuai dengan tujuan agama Hindu.

"Ling Bhatari: uduh sira Sri Jayakasunu, ulun awarah-warah mareng kita. Marmane asiong anyeneng ratu ring Bali agelis pejah, apanira ri kala teluning dunggulan tan ana abaya kala, nora anut kramane nguni. Ya ika ta asing anyeneng ratu, during rong taun mawetu pejah tekaning wadwania kabeh, pada telas pejah ya tiba jaramarana dening pada Batara, apan paranoia kayangan pada Batara. Mwah kabyutan tekaning pangastanan telas pada rusak tan ana kadi ring kuna-kuna. (Sri Jayakasunu, 2a).

Terjemahan:

Bersabda Bhatari Durga: "wahai anakku Sri Jayakasunu sekarang aku memberikan wejangan kepadamu, apa sebab setiap yang menjadi raja di Bali cepat meninggal, sebab pada waktu wuku Dunggulan tidak ada seorangpun yang melaksanakan upacara 
byakala, tidak seperti waktu dulu. Setiap yang menjadi raja di Bali belum dua tahun sudah meninggal serta pengikutnya semua, semua terkena wabah penyakit oleh Tuhan sebab kotornya kayangan dan juga pelinggih-pelinggih semua rusak tidak seperti dahulu.

Tan papegatan ikang marana. Mwang sasab sumarabah amangsa, dene tan ana baktine ring Dewa mwah tan anane yoga samadinia. Tan ana ulah kerta, nora ana ambek rahayu ring wayakalane. Ya ika matmahan kala-kali sumarambah kalane (Sri Jayakasunu, 2b).

Terjemahan:

Alam Semesta tidak henti-hentinya datang bencana dan segala macam penyakit tidak ada pengobatan dari Tuhan dan tidak pernah melakukan semadi dan yoga. Tidak ada perbuatan baik tidak ada tingkah laku yang baik. Itu yang menyebabkan bhuta kala timbul di saat zaman ini.

Kutipan di atas menyampaikan pesan dari Bhatari Durga meminta agas selalu bertingkah laku yang baik. Menjaga kesucian Pura. Agar terciptanya hubungan yang harmonis antara manusia dengan lingkungannya, manusia dengan sesamanya, dan manusia dengan sang Pencipta yang dikenal dengan konsep Tri Hita Karana yang berarti tiga penyebab kebahagiaan di dunia.

\section{PENUTUP}

Interpretasi nilai filosofis dari teks Sri Jayakasunu dan relevasnsinya terhadap hari raya Galungan adalah 1) nilai kebenaran (tatwa) yang mana menunjukan bahwa konsep dari Panca Sradha harus selalu digunakan sebagai landasan kehidupan didunia. 2) nilai kesusilaan yangselalu melaksanakan konsep Tri Kaya Parisudha, dan dalam implementasinya kepada Tri Hita Karana; dan 3) nilai acara (upacara) sebagai sarana mewujudkan syukur dan bakti kepada Tuhan dengan jalan melaksanakan kegiatan Yadnya.

\section{DAFTAR PUSTAKA}

Antara, I Gede. 2005. Sastra Bali Purwa, Teori Apresiasi Pribasa Bali Gending Kidung Karya Sastra Cermin Sosial Budaya. Singaraja: FIP. IKIP.

Ariwati. I Made Sri. 2003. ManusaYadnya. Surabaya :Paramita.

Ariwidayani, AnakAgung, 2013. "Kajian Filosofis Lontar Tattwa Kala”. Denpasar: Skripsi Fakultas Brahma Widya IHDN Denpasar. 
Bakhiar. Amsal. 2012. Filsafat Ilmu. Yogyakarta: PT. Raja Grafindo Persada (Rajawali Press).

Djarwanto. Djamarah. 1984. Pokok-Pokok Metode Riset dan Bimbingan Teknis Penulisan Skripsi. Yogyakarya: Liberty.

Donder, I Ketut, 2006. Brahmavidya: Teologi Kasih Semesta. Surabaya: Pāramita.

Duani, Ni Made. 2013. Makna Filosofis yang Terkandung Dalam Gaguritan Jambanegara. (Skripsi). Denpasar: IHDN Denpasar.

Fathoni. Abdurrahmat. 2006. Metodologi Penelitian dan Teknik Penyusunan Skripsi. Jakarta: Rineka Cipta.

Iqbal. Hasan. 2002. Pokok-Pokok Materi Metodologi Penelitian dan Aplikasinya. Jakarta: Ghalia Indonesia.

Juliantari, Kadek. 2009. “Analisis Karakter Tokoh Cerita Mayadenawa serta Relevansinya dengan hari raya Galungan". Skripsi: IHDN Denpasar.

Kaelan. 1998. Pendidikan Pancasila Yuridis Kenegaraan. Yogyakarta: Penerbit Paradigma.

Teeuw. A. 1984. Sastra Dan Ilmu Sastra, Pengantar Teori Sastra. Jakarta: Pustaka Jaya.

Titib. I Made. 1996. Veda Sabda Suci Pedoman Praktis Kehidupan. Surabaya: Paramita.

Tri Guna. Ida Bagus Gde Yudha. 2000. Teori Tentang Simbol. Denpasar: Widya Dharma. 